with lung cancer and a control group with no lung cancer. The group mean levels both in the morning and in the afternoon were greater in the lung cancer patients, but the range of individual values within each group does not permit the test to be used diagnostically.

Thanks are due to Dr. G. R. Simpson, Dr. A. G. Rothwell, and Dr. L. G. Barnes for assistance with this study, and to Dr. H. D. Purves, Director of N.Z.M.R.C. Endocrinology Research Unit, for help and advice.

\section{REFERENCES}

Caranasos, G., and Ruebner, B. H. (1963). Arch. Path., 76, 263. Cope, C. L. (1966). Brit. med. Y.. 2, 847, 914.
Hatch, H. B., jun., Segaloff, A., and Ochsner, A. (1965). Ann. Surg.161,645 .

James, v. H. T., Townsend, J., and Fraser, R. (1967). F. Endocr., 37,

Liddle, G. W. (1966). Arch. intern. Med., 117, 739.

Liddle, G. W., Givens, J. R., Nicholson, W. E., and Island, D. P. (1965). Cancer Res., 25, 1057 .

McGill, P. E., Greig, W. R., Browning, M. C. K., and Boyle, J. A. (1967). Ann. rheum. Dis., 26, 123.

McHardy-Young, S., Harris, P. W. R., Lessof, M. H., and Lyne, C (1967). Brit. med. 7., 2, 740.

Mattingly, D. (1962). \%. clin Path., 15, 374

Mills, J. N. (1966). Physiol. Rev., 46, 128.

Purves, H. D., and Sirett, N. E. (1967). N.Z. med. 7., 66, 811.

Sandberg, A. A., Eik-Nes, K., Migeon, C. J., and Samuels, L. T. (1956) F. clin. Endocr., 16, 1001 .

Segaloff, A., Hatch, H. B., and Rongone, E. L. (1962). Cancer Chemo-

Sholitan, Lep. J., Incze, J. S., and Werk, E. E., jun. (1961). Cancer, 14. 105 .

Werk, E. E., jun., and Sholiton, L. J. (1960). Cancer, 13, 469.

\title{
Calf Pain in the Post-thrombotic Syndrome
}

\author{
DAVID NEGUS, ${ }^{*}$ M.A., D.M., M.CH., F.R.C.S.
}

Brit. med. Y., 1968, 2, 156-158

Extensive thrombophlebitis of the deep veins of the leg is usually followed by the syndrome of swelling, induration, ulceration, and pain. This pain is of two sorts: firstly, the discomfort which is associated with distended varices and ulceration, and, secondly, the calf pain, which has been described as "bursting" in nature (Bauer, 1948). Other names for calf pain in the post-thrombotic syndrome are "cruralgia orthostatica" (Arnoldi, 1965) and "venous claudication" (Cockett and Lea Thomas, 1965).

Patients with post-thrombotic damage to the deep veins of the leg may be divided into two groups (Cockett and Lea Thomas, 1965). Thrombophlebitis confined to those veins which lie distal to the inguinal ligament (the femoral, popliteal, , and calf veins) is followed by recanalization, which results in valvular incompetence of the deep and perforating veins (Homans, 1917 ; Cockett, 1953). Iliac vein thrombosis, on the other hand, is of ten followed by grossly inadequate recanalization and permanent stenosis (Wanke and Gumrich, 1950; Eufinger, Diethelm, and May, 1961 ; Luke, 1962 ; Cockett, Lea Thomas, and Negus, 1967). This stenosis is commonly, though not invariably, localized to the left common iliac vein, where it is crossed by the right common iliac artery. In spite of collateral formation, stenosis usually results in permanent obstruction to venous return and a rise in pressure in the distal veins (Negus and Cockett, 1967).

No previous attempt has been made to compare the clinical features of these groups of patients, and this paper reports the results of observations and investigations of the clinical features, with particular reference to the incidence, significance, and mechanism of calf pain.

\section{Incidence and Significance of Pain}

Forty-four patients with post-thrombotic damage to the deep vein of the lower limb were divided into two groups on the results of peripheral and iliac phlebography and of venous pressure measurement in the foot and femoral vein (Negus and Cockett, 1967), and from observations made during surgical operation.

Group 1.-Seventeen patients were shown to have incompetence of the peripheral deep veins and perforating veins without functional obstruction to venous return.
Group 2.-Twenty-six patients had stenosis of the iliac veins or inferior vena cava sufficient to cause functional obstruction to blood flow, in addition to peripheral deep-vein incompetence. In one other patient normal peripheral deep veins were associated with proximal obstruction to venous blood flow.

There was no significant difference in age, sex, or age at onset between the two groups.

Studies were also made of five normal subjects and five patients with primary lymphoedema.

\section{Investigations}

History.-Each patient was questioned specifically about pain: its site and nature, precipitating factors, measures taken to relieve it, and the social incapacity which resulted from it.

Physical Examination.-Particular attention was paid to the presence or absence of varicose veins, incompetent perforating veins, ankle ulceration, and swelling of the affected leg.

"Stepping Test."-All 17 group 1 patients and 26 group 2 patients underwent a "standard stepping test," which consisted of marking time at a speed of 80 steps a minute, each foot being lifted to half the height of the opposite knee. Patients were encouraged to continue the exercise until they complained of severe discomfort.

\section{Results}

History.-Only one patient in group 1 complained of more than " heaviness" or fatigue, and most stated that, apart from the ulcer, they were perfectly comfortable. One worked as a woodman, walking eight to nine miles (13 to $14.5 \mathrm{~km}$.) a day, and another walked the beat as a special constable after his day's work as an accountant. No patient in group 1 was forced to change his employment. Every patient with post-thrombotic obstruction to venous return (group 2) complained of calf pain, which was exacerbated by exercise and which was often described as "bursting" in nature. The pain was usually confined to the calf and was occasionally described as spreading to the thigh. It was sometimes felt on prolonged standing, and

* Lecturer, Department of Surgery, St. Thomas's Hospital, London S.E.1 
it usually started after walking $\frac{1}{4}$ to 1 mile (400 to $1,600 \mathrm{~m}$.), or a shorter distance if climbing was involved. The patient was forced to limp, and eventually to stop and rest, preferably but not essentially with the leg raised. The pain, together with swelling and ulceration, was severe enough in one patient to require amputation. Less severe forms of disability included difficulty in shopping and in looking after children, difficulty at work necessitating a change to more sedentary employment, and loss of recreational activities such as playing football or dancing. The degree of each patient's disability and its social significance have been assessed, and results are shown in Table I.

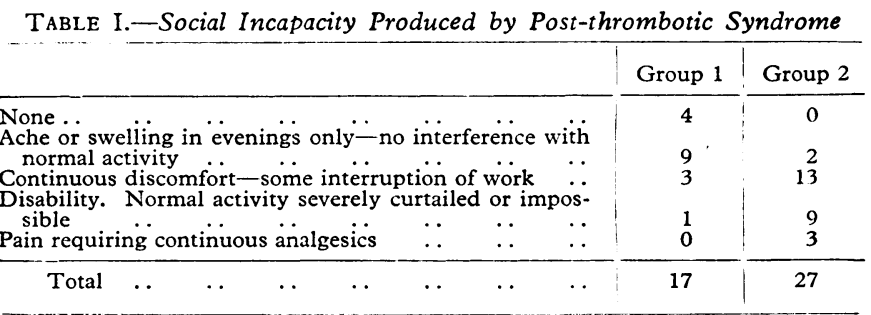

Physical Examination.-Incompetent long or short saphenous veins were present in 10 of the group 1 patients, and 16 presented with an ulcer above the medial malleolus. One or more incompetent perforating ankle veins were demonstrated in all but one of these patients. Varicose veins were present in seven of the group 2 patients and ankle ulceration in 10 .

Usually there was greater swelling of the leg in patients with venous obstruction than in those with peripheral deep vein incompetence alone (Cockett et al., 1967), but this was not as a rule unsightly.

Stepping Test.-All 26 patients with venous obstruction (group 2) complained of pain in the calf before the end of the five-minute period of exercise, and most of them were unable to continue "marking time" because of the severity of the pain. Six also complained of some pain on standing still. No patient with peripheral deep vein incompetence alone (group 1) complained of pain, and most were able to complete five minutes' exercise. No normal subject or patient with lymphoedema complained of any discomfort.

\section{Mechanism of Pain}

Possible underlying causes for the calf pain which occurs on exercise in patients with post-thrombotic venous obstruction are: (1) that it is the direct result of nociceptor stimulation in the wall of the distended vein, and (2) that the rise in venous pressure in the presence of obstruction results in arteriolar insufficiency and that the pain is therefore the result of muscle ischaemia.

The first possibility-that pain is produced by stretching of the vein wall-has been investigated by J. C. Milliken (personal communication, 1966). He found that distension of a superficial vein by a Fogarty catheter inserted under local anaesthesia usually caused pain that was localized to the position of the balloon.

When measuring femoral venous pressure in patients with suspected iliac vein or inferior vena caval obstruction (Negus

TABLE II.-Resting and Excrcising Femoral Venous, Pressures in Four Patients who Developed "Venous Claudication" While Exercising \begin{tabular}{c|c|c|c|c|c}
\multicolumn{3}{c}{ Against Resistance in the Supine Position } \\
\hline
\end{tabular} and Cockett, 1967) it was noticed that four developed calf pain while exercising in the supine position. The venous pressure at which pain occurred was recorded in order to find out whether this was likely to be severe enough to cause painful venous distension. It was found that pain sufficient to prevent further exercise occurred at a mean pressure of $17 \mathrm{~mm}$. $\mathrm{Hg}$ (range 11-22 mm. Hg) (Table II).

The venous pressures associated with calf pain in these patients were much less than those present in the veins of the normal lower leg in the erect motionless position, or those present during exercise in the leg with venous valvular incompetence $(50-90 \mathrm{~mm}$. $\mathrm{Hg}$ ). It can be argued that these observations are of doubtful value, as venous pressures were measured in the femoral veins rather than in the calf veins, which were most closely related to the site of pain. It seems unlikely, however, that the pressure gradient between calf and femoral veins in the supine position was more than a few $\mathrm{mm}$. $\mathrm{Hg}$, and though conclusive evidence is lacking, it seems improbable that the increased pressure, and consequent venous distension, produced by proximal venous obstruction are sufficient in themselves to account for the calf pain.

The second possibility-that in the presence of obstruction the rise in venous pressure opposes arteriolar inflow to the muscle and the pain is the result of muscle ischaemia-has been tested by measurement of xenon-133 clearance from the calf muscle during exercise in the upright position in four patients with unilateral post-thrombotic iliac vein obstruction. Muscle blood flow was measured by a modification of the xenon-133 clearance method of Lassen, Lindbjerg, and Munck (1964), which has been described elsewhere (Negus, 1967). The range of calf muscle blood flow was found to be from 20.9 to $52.5 \mathrm{ml} . / 100 \mathrm{~g}$. muscle/minute. In no patient was there any significant difference between the xenon-133 clearance from the normal leg and that from the leg with venous obstruction $(0.1<P<0.2)$, nor was any change seen in the rate of clearance in the presence of pain.

\section{Discussion}

It seems likely that "bursting pain" (Bauer, 1948), " cruralgia orthostatica" (Arnoldi, 1965), and "venous claudication" (Cockett and Lea Thomas, 1965) are one and the same thing. In describing this pain Bauer thought that as it was a purely subjective symptom it was of little value in the assessment of patients. As the pain of "intermittent claudication" is commonly used in assessing patients with arterial insufficiency, there seems little reason why "venous claudication" should not be used for the same purpose.

These results show that severe calf pain was confined to those patients with functional obstruction to venous return. Patients with simple post-thrombotic incompetence of the peripheral deep veins often complained of local discomfort in the region of varices or ulceration, but never of calf pain on walking. In fact the pain in and around the ulcer was often relieved by exercise.

By contrast, the calf pain associated with proximal venous obstruction was invariably exacerbated by exercise. The pain was sufficient to curtail activity in most patients with venous obstruction, and none were able to complete the five-minute stepping test. Patients with peripheral venous incompetence but without proximal obstruction did not experience exercising pain, none were forced to change their employment or leisure activities, and all were able to complete the stepping test.

The name "venous claudication" is appropriate in that it emphasizes the relation of this pain to exercise. The term is used in its true sense-claudicare, to limp-and there is no association between this pain and the "intermittent claudication" of arterial insufficiency.

It has been shown that, of 27 patients with obstruction to venous return, ankle ulceration was present in only 10 and 
varicose veins in seven. Most patients had relatively normallooking legs apart from some swelling. It must be emphasized that the primary purpose in the treatment of these patients is to relieve pain. The appearance of the leg is of secondary importance. Successful operative relief of venous obstruction results in the relief of "venous claudication" (Cockett, 1967), and, though swelling of the leg is usually little if at all affected, patients are well satisfied to be rid of the intractable and incapacitating pain.

The mechanism of "venous claudication" remains obscure. The results of these investigations do not indicate distension of the vein wall as a likely cause, nor does ischaemia of the calf muscle seem responsible. Other possible underlying causes for the pain are that it is either the result of increased pressure or that it results from the accumulation of tissue metabolites in the presence of venous obstruction. No investigation of these possibilities has so far been undertaken.

Though the mechanism by which calf pain is produced remains unknown, the present study shows that this pain is confined to patients in whom post-thrombotic damage to the veins of the lower limb has resulted in occlusion or stenosis sufficient to cause functional obstruction to venous return. Those patients whose post-thrombotic damage consisted only of incompetence of the peripheral deep veins did not experience this severe and incapacitating pain.

\section{Summary}

The clinical features of 27 patients with post-thrombotic obstruction to the iliac veins or inferior vena cava, compared with those of 17 patients with post-thrombotic incompetence of the peripheral deep veins alone, have shown that the chief dis- tinguishing feature is calf pain on exercise, which occurs in patients with iliac venous obstruction.

The pain, "venous claudication," is usually severe enough to interfere with work and leisure activities, and usually constitutes a greater disability than varices, swelling, or ulceration.

The mechanism of pain production is obscure. There is no evidence that venous distension or muscle ischaemia is responsible.

A patient with the "post-phlebitic syndrome" who can mark time briskly for five minutes is unlikely to have significant obstruction to venous return.

I am grateful to Mr. F. B. Cockett for allowing me to investigate patients under his care and for his constant encouragement and advice. Femoral venous pressure measurements were performed in the department of medicine, St. Thomas's Hospital, by permission of Professor W. I. Cranston and with the help of Mr. R. W. Hall. Isotope studies were carried out with the help of Dr. T. M. D. Gimlette. This assistance is acknowledged with thanks.

\section{REFERENCES}

Arnoldi, C. C. (1965). Acta chir. scand., 129, 57

Bauer, G. (1948). 7. int. Chir., 8, 937

Cockett, F. B. (1953). M.S. Thesis, London

Cockett, F. B. (1967). Brit. F. Surg., 54, 891

Cockett, F. B., and Thomas, M. L. (1965). Brit. F. Surg., 52, 816.

Cockett, F. B., Thomas, M. L., and Negus, D. (1967). Brit. med. F., 2; 14.

Eufinger, H., Die:helm, L., and May, E. (1961). Bruns' Beitr. klin. Chir., 203,152 .

Homans, J. (1917). Surg. Gynec. Obstet., 24, 300.

Homans, N. A., Lindbierg, J., and Munck, O. (1964). Lancet, 1, 686

Luke, J. C. (1962). 7. cardiovasc. Surg., Torino, 3, 411.

Luke, J. C. (1962). F. cardiovasc. Surg., Torino, 3, 41.

Negus, D. (1967). D.M. Thesis, University of Oxford.
Negus, D., and Cockett, F. B. (1967). Brit. f. Surg., 54, 522.

Negus, D., and Cockett, F. B. (1967). Brit. F. Surg., 54, 522.
Wanke, R., and Gumrich, H. (1950). Zbl. Chir., 75, 1302.

\section{Preliminary Communications}

\section{Urinary Oestriol after Intra-amniotic Injection of Oestriol Sulphate}

Brit. mcd.7., 1968, 2, 158-159

It is now agreed that the foetus, as well as the placenta, plays a part in the biogenesis of the large amounts of oestriol excreted in the mother's urine during pregnancy. In the foetal circulation and liquor amnii the oestriol is largely present as oestriol sulphate (Diczfalusy et al., 1961a, 1961b, 1961c). In the placenta and maternal urine, on the other hand, the main conjugates are oestriol glucosiduronates. It is likely that desulphurylation and reconjugation as glucosiduronate are involved in the process whereby oestriol finds its way from the foetal compartment to the maternal urine. Studies of placental enzymology show it is probable that a considerable part of this takes place in the placenta.

We have been exploring the possibility that a sudden load on this transfer system in late pregnancy may constitute a useful test of placental function. To this end, doses of $100 \mathrm{mg}$. of oestriol sulphate have been injected direct into the liquor amnii and the output of oestriol in the maternal urine examined. To our knowledge such pharmacological doses of oestriol have not been used before; the metabolic studies having been done in early pregnancy with tracer amounts of radioactive steroids. The experiments to determine the normal turnover of oestriol sulphate are still in progress, but the initial results appear to be of sufficient interest to warrant a preliminary communication.

\section{Patients}

The study was carried out on five voiunteers, all of whom were within a week on either side of their expected date of delivery. Four were multiparae, of whom two had a mild essential hypertension. The only primigravida and the remaining two multiparae were normal in all respects. All patients subsequently gave birth to normal live babies.

\section{Experimental Design and Methods}

All the patients were admitted to a metabolic research unit and given a high fluid intake. Urine collections, in periods of four hours, were made for 40 to 48 hours before injection. The overnight collection periods were increased to eight hours. Duplicate oestriol assays were done on each four-hour specimen, the method of Klopper and Wilson (1962) being used. This made it possible to calculate the mean four-hourly oestriol output before injection. Uterine contractions, measured by external tocograph, were recorded at intervals, particularly in the last two to four hours before oestriol injection. A transabdominal amniocentesis was then done, and $100 \mathrm{mg}$. of oestriol sulphate dissolved in $10 \mathrm{ml}$. of sterile neutral distilled water was injected direct into the liquor amnii. After injection further recordings of uterine contractions were made, and the urine collections, in four-hour periods with eight-hour overnight collections, continued for a further 36 hours. The recovery of injected oestriol during any period was calculated by subtracting the mean preinjection value of the patient from the amount of urinary oestriol found in that period. 